\section{Policies and evidence}

In February of 1971, the final draft of the Forest Policy Statement was issued to all voting members, together with a ballot requesting members to vote approval or disapproval, and requesting comments on suggested additions, deletions, or amendments.

A return of 516 completed ballots showed the interest and concern of $29 \%$ of the voting membership, of which a healthy $63 \%$ approved without qualification. This low response is disappointing to the Executive. Of the 516 ballots, $93 \%$ approved, or approved with certain exceptions.

The fact that all those who returned ballots were intensely interested in the form, intent, and presentation of the 20 items in the statement is proven by the 60 some odd pages of comments. Thus, the Institute now has the necessary framework for a Statement of Forest Policy. It remains for the Executive Committee to consider the comments for inclusion, and to "polish and prepare" item by item for final publication, acccrding to the suggestions submitted. However, the Statement of Forest Policy for the Canadian Institute of Forestry is now a fact.

I have now disbanded the original Policy Committee, at the request of Ted Fellows, Chairman, and will appoint a new Committee to hopefully prepare the Statement for release to all members at the Annual Meeting. We all owe a debt of gratitude to Ted for his devotion and effort to the production of the present Statement, and to all CIF activities, over the past five years while he served on the Executive.

I was impressed by a recent address given by the Hon. Jack Davies to the Canadian Forestry Association of British Columbia's Annual Meeting in Vancouver, where he stated that foresters have impressed him greatly while he has been Minister of Fisheries and Forestry. He has been impressed, he said, by the long- range thinking of foresters, and their efforts to put good environmental practices into effect. He summed up by saying that, in his opinion, "Foresters are the Statesmen of the Environment".

On behalf of the Institute, I recently submitted a letter to the Prime Minister and the Hon. Jack Davies concerning Science Policy Reports No. 8 and No. 9. I informed the Prime Minister that we endorsed most of the findings and recommendations of these Reports, and then I commented on the necessity of providing adequate funding for many of these recommendations. The Reports indicated that Societies should review progress in their field and make recommendations for improving effectiveness. We indicated that the Canadian Institute of Forestry will soon have it's Canadian Forestry Education Study ready for publication. This will provide an in-depth analysis of the needs in education to meet the future requirements of $\mathrm{Na}$ tural Resource Managers.

I have also had correspondence with the President of the Canadian Broadcasting Corporation, Mr. G. F. Davidson, concerning the program, "This Land", of February 17, 1971. We indicated that there were many facets of forestry left unsaid in their original program, and we welcome the opportunity to cooperate in the production of a "companion" program on Forestry in Canada.

Norm Kissick, Chairman of the National Parks Policy Committee, has indicated to me the difficulty in pursuing the aims and objectives of his Committee; namely, to present a positive approach to the Policies proposed by the $\mathrm{Na}$ tional Parks Branch, and to the other Conservation groups. One of his major concerns, related to the management of forested lands incorporating recreation needs, is the lack of examples of acceptable forest management. As foresters, we have repeatedly stated that such management is pos- sible, that we can carry out practices which would permit recreation and timber production activities to be carried out without conflict, yet, when pressed to "show me examples" of such practices, we have very few to offer. In Norm's view, his Committee must consider this matter and make recommendations for research and "demonstration" at the Annual Meeting.

In a recent discussion with the President of the Sierra Club of B.C., I was told that his organization has very little faith in Professional Foresters in Canada, mainly because of the lack of evidence that we could put in front of his members, indicating that we know what we are talking about. In other words, he stated that our present harvesting practices, and the research that has been carried out and published, has never produced results substantiating that yields from our second and third crops will be any greater than that provided by nature in the initial instance. In fact, his members submit that yields will slowly decline on forest lands in Canada under Professional Forestry Managers. Norm Kissick and his Committee, also intend to discuss attitudes such as these in their session to be held in Victoria.

The Annual Meeting is progressing very favourably, and an excellent program is presently being formulated. Advice will be forthcoming from the Local Section in the near future, and a record turnout is forecast. Therefore, please make plans to be in attendance in Victoria, in October, during B.C.'s Centennial Year.

W. G. Burch, R.P.F. President

\section{Have you voted?}

Remember to vote before June $\mathbf{3 0}$ for members of the Executive. Ballot forms and biographies of the nominees were mailed in April. Voting is required for the positions of $1 \mathrm{st}$ Vice President (J. Walter Giles, currently 2nd Vice President) and 2nd Vice President (Patrick J. B. Duffy or Gordon F. Weetman). 